\title{
ANALYSIS OF PROBLEMS FACED BY SPECIAL EDUCATION TEACHER IN TEACHING MULTIPLE DISABILITIES STUDENTS
}

\author{
Azhar Alias ${ }^{a}$, Norshidah Mohamad Salleh \\ ${ }^{a}$ Sekolah Rendah Pendidikan Khas Muar (P), Malaysia \\ ${ }^{b}$ Universiti Kebangsaan Malaysia, Malaysia \\ E-mail : jaaxtream@gmail.com
}

\begin{abstract}
This study was conducted based on Maslow's Motivational Theory that focusing on Maslow's Hierarchy of Needs. This survey had implemented questionnaire instrument that had been adapted from Oklahoma Office of Handicapped Concerns: 2001-2002 Disability Assessment Study. Interview protocol was adapted from National Center for Postsecondary Improvement and was implemented to identify other problems. The respondents were 66 special education teachers from 18 schools in Muar distric state of Johore Malaysia and 18 others were interview session that were choosen using purposive sampling. The datas were analyzed using the IBM SPSS Statistic Version 22 by comparing mean and the findings from the interview were analyzed narratively. Both findings were devided into 3 levels which were low, medium and high according to mean value and percentage of respondent agreements. This study had found 12 problems (mean $=3.97$, s.d $=0.916$ ) and the 4 main problems according to priority were (1) lack of specific teaching aids (mean=4.15, s.d=0.808) (2) low self motivation and self confident (mean=4.14, s.d=0.857) (3) lack of aids support (mean $=4.12, \mathrm{~s} . \mathrm{d}=0.851$ ) (4) communication problems (mean=4.09, s.d=0.872). The findings from the interview had came up with 15 problems and the 5 main problems according to priority were (1) emotional disturbance and lack of concentration (2) non-condusive environment in the classroom (3) communication problems (4) low cognitive level (5) lack of specific teaching aids. These findings were seen as good indicators for the authorities and special education teachers to develop and improve the education system, teaching pedagogy and high quality level of profesionalism among special education teachers.
\end{abstract}

Keywords: multiple disabilities, severe disabilities, needs analysis.

Multiple disabilities were defined as a person with two or more disabilities (Norshidah \& Manisah 2010). Multiple disabilities were also the combination of disabilities that leads to specific education needs and can't be adapt to special education programme for one type of disability (Centre for Parents Information and Resources 2013). However, this definition did not include the deaf-blind category (IDEA 2004) but it was accepted in Malaysia. While severe disabilities refer to person with severe disabilities and need different measurement and evaluation in the aspects of politic, social, laws, education, health and financial in order to ensure their rights in education effectively and with best quality (Manuel et al. 2014).

There were two examples of disabilities combinations namely the combination of intellectual disability with blindness and the combination of intellectual disability with physical impairment (Centre for Parents Information and Resources 2013). However, special education students in Malaysia were devided into three main disability categories that were the hearing impairment, visual impairment and learning impairment. Each multiple disability child had their own unique and specific characteristics. Although there were various characteristics among individual with multiple disabilities that caused by multiple disabilities combination, there were still general specific characteristics that can be observe such as: a) Limited speech and communication ability; b) Basic physical mobility disability; c) The tendency to lost basic skills by the lack usage of the skills; d) Difficulty in generalizing skills from one situation to another situation; e) Need support in daily life main activities (Norshidah \& Manisah 2010).

These general specific characteristics were important indicators in developing programme, teaching pedagogy and curriculum that compatible for multiple disabilities students. Each disability was caused by specific factors. The causes of multiple disabilities were chromosome abnormality, pre-matured birth, problems after birth, delay in brain development, germ and virus infection, genetic disorder and injury that caused by accident (Centre for Parents Information and Resources 2013).

Education for multiple disabilities students is very important and in this case, special education teachers 
play important role in educating, passing on knowledge dan skills towards special needs students. Special education teachers should have the ability to manage the students with multiple range and disability range starting from mild to profound (Emery \& Vandenberg 2010). However, this disabilities combination had caused a lot of problems to the special education teachers towards effective teaching and learning because they need specific education needs and can't be adapt to special education programme for one type of disability. Special education teachers should be wise in identifying and understanding the needs of multiple disabilities children because they have their own skills, strength and education needs (Centre for Parents Information and Resources 2013). So, all teachers should try to identify and understand the strength and interest of the children in order to motivate them and increase the quality of the education for them. Education system for special needs students that had implemented various effective methods or techniques and comprehensive evaluation or assessment will benefit the students. Students with severe learning impairment without speech can get benefit from the education system that they involved if the teacher and students use augmentative and alternative communication in teaching and learning process (Noraini et al. 2012).

Special needs children should involve actively in the process of assessment and intervention to ensure that they receive effective learning (Susheel et al. 2015). Rather than that, effective interaction and communication are important to special needs children (Pinar et al. 2014; Nijs \& Maes 2016). Special education teachers should also understand deeply about Individual Education Plan (IEP). IEP is an important element to determine goal and itemize the implementation of education according to the objective that had been defined. Although quality of the IEP is a performance assessment aspect that is not significant but the education system still need to provide professionalism development programme and increase the IEP observation quality in order to increase the achievement among special needs students and to ensure that the goal and service stated in the IEP were observed and implemented accordingly (Tamika et al. 2013).

Multiple disabilities students need additional modification and accommodation in the classroom that suit their needs. This type of students could not complete their own task independently and they need support or guidance. Assistive Technology (AT) is a teaching aid that really need by the multiple disabilities students. Without assistive technology, students will have difficulties to complete tasks given. Assistive technologies are teaching aids such as computer, alternative communication system and et cetera. Thus, special education teachers should have mastered the skills in conducting assistive technology in teaching and learning pedagogy. While, Personal Digital Assistant (PDA) was developed to increase the playing ability among multiple disabilities children and to help in their rehabilitation proses (Proenca et al. 2014). Thus, assistive technologies have the potential to improve standard of living and to get rid of difficulties in learning among learning impairment students (Bradley et al. 2012; Rufus et al. 2015).

Maslow's Motivational Theory believed that human always motivated to achieve dan fulfill their self needs. This is shows in Maslow's Hierarchy of Needs that showing the levels of human needs starting from physiology, safety, love and trust, self-appreciation and finally self-fulfillment needs. When the basic level of human need was fulfill, the next level of need become the next priority (Xiaoqin 2016; Maslow 1954). If human needs were not fulfill according to the hierarchy, problems or conflicts will occur and that particular person will not be able to shift to another level of needs. Thus, it is important that this survey was based on Maslow's Motivational Theory to identify and determine the priority level of the problems faced by special education teachers in teaching multiple disabilities students in order to overcome the problems according to the hierarchy of needs.

\section{Diagram 1.0 : Maslow's Hierarchy of Needs}

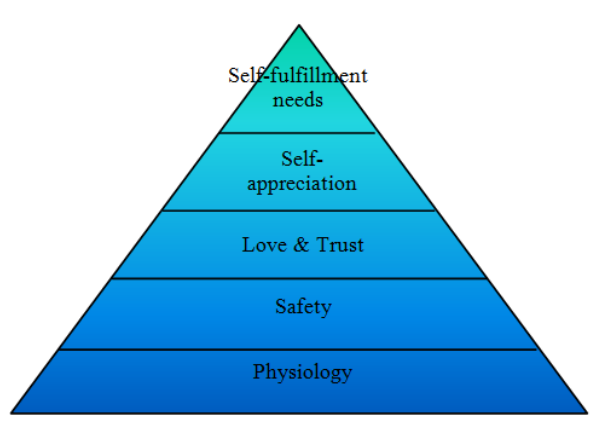

Sourse : www.simplypsychology.org (2016)

The small population of multiple disabilities children had limit the total empirical research. Thus, understanding the problems and needs of the multiple disabilities children were so limited in Malaysia. Therefore, research about problems faced by special education teachers in teaching multiple disabilities students is a must although their population was small because every child deserves fairness and equality towards opportunity to receive high quality education (NCLB, 2001). Improving education for special needs children is an important element in national policy to ensure equality of opportunity, full participation, ability to be independent and adequate ecomonic for individual with disability (IDEA 2004).

Early survey had found out that the percentage 
of multiple and severe disabilities students over the total special needs students in Muar district for the year 2016 was $9.78 \%$. This percentage was a lot higher than in the developed country such as USA that only obtained the percentage of $2 \%$ for the year 2014 (NCES 2016) although there was a bit different of multiple disabilities definition between IDEA (2004) and Person with Disabilities Act 2008 (Act 685) because IDEA (2004) had excluded the category of deaf-blind from the multiple disabilities category. Thus, this high percentage shows that there is a need to do research in deep understanding and in details regarding multiple disabilities children in order to ensure that they receive appropriate education level in accordance to their disabilities and they will not be having education or career dropout. The main objectives of this research are to: a) Identify the problems faced by special education teachers in teaching multiple disabilities students; b) Determine the priority level of the problems faced by special education teachers in teaching multiple disabilities students.

\section{METHODOLOGY}

The research design of this study was quantitative survey design. The purpose of the survey is to describe, compare and predict the attitudes, opinion, behaviour and characteristics of the population (Sherri 2006). Therefore, the implementation of this research design is coincide with the research purposes; to identify and determine the priority level of the problems faced by special education teachers in teaching multiple disabilities students.

The study began by analyzing a number of journal articles to obtain preliminary information regarding the problems faced by special education teachers in teaching multiple disabilities students. The search results were found nearly 32 articles related to children with multiple disabilities, children with severe disabilities or special education teacher. After the screening had been done, only 13 journal articles were selected for analysis. All 13 journal articles are divided into two forms; empirical research study and conceptual studies with 11 in the form of empirical studies and another 2 were in conceptual form. Location for the empirical study is dominated by the USA with 4 journal articles and 3 journal articles were from Malaysia. While Canada, Romania, Turkey and Netherlands respectively with 1 journal article each. This shows that the country of USA made a lot of study regarding children with multiple disabilities compared to other countries, including Malaysia. Research design for the journal articles are mostly empirical surveys and qualitative case studies. There were only two journal articles conducting quantitative study with the number of respondents 150 people and 326 people respectively. The results of the review of journal articles have found 12 problems faced by special education teachers in teaching multiple disabilities students; (1) incompatibility of curriculum (2) the absence of teaching module (3) the absence of specific trainings or courses (4) low self efficacy (5) lack of specific teaching aids (6) lack of aids support (7) low self motivation and self confident (8) communication problems (9) low mobility skills (10) non-condusive environment in the classroom (11) low sensitivity among school administrators and mainstream teachers (12) incompatibility of co-curricular activities.

In addition, the initial survey was also conducted in schools of Muar district that have classes or special education programmes to obtain the enrollment of multiple and severe disabilities students for the year 2016. 36 schools were identified having a special education programme by the division of 25 primary schools and 11 secondary schools with the total of 695 special education students attended. A total of 18 schools were found to have pupils with multiple and severe disabilities by the division of 11 primary schools and 7 secondary schools. The results of this initial survey found that the percentage of students with multiple and severe disabilities compared to overall special education students in Muar for 2016 is $9.78 \%$. This percentage is much higher when compared to developed countries such as United States which recorded the percentage of $2 \%$ in 2014 (NCES 2016).

Table 1.0: Number of students with multiple disabilities in Muar district for the year 2016

\begin{tabular}{lc}
\hline \multicolumn{1}{c}{ Category } & Total \\
\hline Deafblind & 1 \\
Deaf and Learning Impairment & 4 \\
Blind and Learning Impairment & 7 \\
Physical Impairment and Learning & 21 \\
Impairment & \\
Severe Disabilities / Mental Retardation & 35 \\
\hline Overall Total & 68 \\
\hline
\end{tabular}

Questionnaire for this study was adapted from the Oklahoma Office of Handicapped Concerns: 20012002 Disability Assessment Study comprises four constructs of socio-demographic information, analysis of the needs of individuals with disabilities, analysis of the problems faced by special education teachers and analysis of the needs of special education teachers in teaching multiple disabilities students. However, this study only analyzed 2 constructs (socio-demographic information and analysis of the problems faced by special education teachers). Socio-demographic information consists of 15 items, but only four items were selected for the analysis (gender, age, education level and teaching experience). Whereas, problem analysis consists of 12 items that had been obtained from the analysis of journal articles and the items 
comprise 12 questions using a Likert scale of 1 to 5 (1-strongly disagree, 2-disagree, 3-somewhat disagree, 4-agree, 5-strongly agree) and one part of open-ended question. This questionnaire has gained validity and reliability with Cronbach alpha values 0.932 and has been ratified by five experts, namely a lecturer in the field of special education, 2 language specialist teachers and 2 teachers expert in the field of special education.

Interview instruments was adapted from interview protocol of the National Center for Postsecondary Improvement (2003) to identify other problems faced by special education teachers in teaching multiple disabilities students and this instrument have gained validity and reliability from a special education lecturer, a teacher expert in the field of special education and a language specialist teacher. The instrument consists of 3 constructs (background of the respondents, the problems faced by teachers and the needs of teachers in teaching multiple disabilities students). However, this study only focused on 2 construct that were the background of the respondent and the problems faced by the teachers. The construct of the respondents' background consists of 4 questions and the construct of the problems faced by the teachers consists of 2 questions.

This study had chosen special education teachers that had experiences in teaching students with multiple disabilities. The sample must have the characteristics or attributes of the population to be studied so that the information obtained through the survey can give a statement and an overview of the overall population studied (Sabitha, 2006). The sample for the survey were 66 special education teachers from 18 schools that had been identified having multiple disabilities students. The findings of the socio-demographic data reveals that the sample consisted of women (percent $=72.7 \%, n=48$ ) and men (percent $=27.3 \%, \mathrm{n}=18$ ). The percentage of respondents was higher in the range of middle age of 36 years to 54 years (percent $=57.6 \%, n=38$ ) and followed by the young age of below 35 years (percent $=36.6 \%$, $\mathrm{n}=24)$ and the old age of 55 years and above (percentage $=6.1 \%, \mathrm{n}=4$ ). In terms of education level, the respondents consist of graduates (percent $=84.8 \%$, $\mathrm{n}=56$ ) and non-graduates (percent $=15.2 \%, \mathrm{n}=10$ ). While in terms of teaching experiences, teachers with experiences of less than 6 years (percent $=37.9 \%$, $\mathrm{n}=25), 7$ years to 12 years (percent $=27.3 \%, \mathrm{n}=18$ ) and has more than 13 years experiences (percent $=34.8 \%$, $\mathrm{n}=23$ ). Meanwhile, respondents of this interview is composed of 18 special education teachers selected using purposive sampling with an age range between 28 years to 55 years and was also composed of 9 males and 9 females. 10 of them teaching in primary school and 8 of them teaching in secondary school.

\section{FINDINGS AND DISCUSSION}

\section{Findings}

The data obtained from the questionnaire were analyzed descriptively by percentages and comparing mean using IBM SPSS Statistics software Version 22. Data from the first construct of socio-demographic information is analyzed to determine the percentage of 4 items (gender, age, education level and teaching experience). Meanwhile, data from construct of analysis of the problems faced by the teachers were analyzed by comparing mean and each acquisition referred to the 3 quartiles of mean [First Quartile: 1.0-1.6 (low); Second Quartile: 1.7-3.3 (moderate); Third Quartile: 3.4-5.0 (high)] to show the degree of strength of the problems. The data from the interview sessions were analyzed narratively according to the findings of certain themes and the percentage of respondents referred to the 3 quartiles of percentage [First Quartile: 0-33\% (low); Second quartile: 34-67\% (moderate); Third Quartile: $68-100 \%$ (high)] to show the degree of strength of the problems. Both findings (questionnaire and interview) will also be analyze according to priority level (low, moderate and high).

The study is divided into two aspects, namely the priority level of the problems and other related problems. The first findings (questionnaires) aimed to fulfill the main objectives of the study and the findings of the interview is an added value to the key findings of the study.

\section{The Priority Level Of The Problems}

The literature review that was conducted using the method of systematic review had identified issues of special education teachers in teaching multiple disabilities students. Meanwhile, a descriptive analysis of the third construct (analysis of the problems faced by the teachers) had been able to determine the priority level of the problems as shown in Table 2.0. Based on Table 2.0, it appears that the overall mean of 3.97 located on the third quartile (3.4-5.0). This shows that the problems faced by special education teachers in teaching students with multiple disabilities are at a high level. At the same time, it gave an indication that the reality of special education teachers in Muar facing high degree of problems in teaching multiple disabilities students.

All the 12 problems were on the third quartile (3.45.0) and indicates that all of the problems at the high degree of strength and once again, it showed that all the 12 issues were the main problems faced by special education teachers in teaching students with multiple disabilities. However, there are four main problems that most significantly according to the priority level (low, medium and high) namely (1) the lack of teaching aids 
(mean $=4.15$, s.d $=0.808)$ (2) low motivation and selfconfidence $($ mean $=4.14$, s.d $=0.857)$ (3) the lack of aids support (mean=4.12, s.d=0.851) and (4) communication problems $($ mean $=4.09$, s.d $=0.872)$. This shows that the problem of special education teachers in teaching students with multiple disabilities are related to aspects of teaching aids and students' self-problems in terms of self-motivation, self-confidence and communication. Meanwhile, 4 problems were at the level of low priority, were the incompatibility of co-curricular activities (mean=3.92, s.d=0.917), incompatibility of curriculum (mean=3.89, s.d=1.025), the absence of teaching module (mean $=3.85$, s.d $=0.932$ ) and the absence of specific trainings or courses (mean $=3.59$, $\mathrm{s.d}=1.123$ ). This finding indicates that the problems were at the low priority level where it associated with the education system that includes curriculum, modules, co-curricular, trainings and courses.

Table 2.0: The mean value, standard deviation and the priority level for each item of the problems faced by teachers in teaching multiple disabilities students.

\begin{tabular}{|c|c|c|c|c|}
\hline No & Item & Mean & $\begin{array}{l}\text { Standard } \\
\text { deviation }\end{array}$ & $\begin{array}{l}\text { Priority } \\
\text { level }\end{array}$ \\
\hline 1 & $\begin{array}{l}\text { Lack of specific } \\
\text { teaching aids. }\end{array}$ & 4.15 & 0.808 & High \\
\hline 2 & $\begin{array}{l}\text { Low self motivation } \\
\text { and self confident. }\end{array}$ & 4.14 & 0.857 & High \\
\hline 3 & Lack of aids support. & 4.12 & 0.851 & High \\
\hline 4 & $\begin{array}{l}\text { Communication } \\
\text { problems. }\end{array}$ & 4.09 & 0.872 & High \\
\hline 5 & Low mobility skills. & 4.03 & 0.841 & $\begin{array}{l}\text { Moder- } \\
\text { ate }\end{array}$ \\
\hline 6 & $\begin{array}{l}\text { Low sensitivity } \\
\text { among school } \\
\text { administrators and } \\
\text { mainstream teachers. }\end{array}$ & 4.02 & 0.953 & $\begin{array}{l}\text { Moder- } \\
\text { ate }\end{array}$ \\
\hline 7 & $\begin{array}{l}\text { Non-condusive } \\
\text { environment in the } \\
\text { classroom. }\end{array}$ & 3.95 & 1.014 & $\begin{array}{l}\text { Moder- } \\
\text { ate }\end{array}$ \\
\hline 8 & Low self efficacy. & 3.94 & 0.802 & $\begin{array}{l}\text { Moder- } \\
\text { ate }\end{array}$ \\
\hline 9 & $\begin{array}{l}\text { Incompatibility } \\
\text { of co-curricular } \\
\text { activities. }\end{array}$ & 3.92 & 0.917 & Low \\
\hline 10 & $\begin{array}{l}\text { Incompatibility of } \\
\text { curriculum. }\end{array}$ & 3.89 & 1.025 & Low \\
\hline 11 & $\begin{array}{l}\text { The absence of } \\
\text { teaching module. }\end{array}$ & 3.85 & 0.932 & Low \\
\hline 12 & $\begin{array}{l}\text { The absence of } \\
\text { specific trainings or } \\
\text { courses. }\end{array}$ & 3.59 & 1.123 & Low \\
\hline & Total & 3.97 & 0.916 & High \\
\hline
\end{tabular}

\section{Other Related Problems}

The findings from the interview sessions over 18 special education teachers had displayed 15 problems faced by special education teachers in teaching students with multiple disabilities. 7 of the problems corresponds to the problems as there were in the Third Construct (Analysis of Problems) and 8 of them were other related problems that were emotional disturbance and lack of concentration, low cognitive level, lack of support from parents, discipline problems, the absence of intervention programs and therapies, emotional instability among teachers, unassertive among teachers.and low understanding about students with multiple disabilities. According to the approval of the respondents, the problem of emotional distress and lack of concentration was at the Second Quartile (34-67\%), indicating a moderate degree of strength. Meanwhile, the other problems that were at the First Quartile (0$33 \%$ ) showed a low degree of strength. This suggests that emotional disturbance and lack of concentration is a problem frequently encountered by special education teachers compared to other related problems.

Table 3.0: Percentage of respondents approval and priority level for each item of the problems faced by special education teachers in teaching multiple disabilities students.

\begin{tabular}{|c|c|c|c|}
\hline No & Item & $\begin{array}{c}\text { Percentage of } \\
\text { Respondents } \\
\text { Approval }\end{array}$ & $\begin{array}{c}\text { Priority } \\
\text { level }\end{array}$ \\
\hline 1 & $\begin{array}{l}\text { Emotional disturbance } \\
\text { and lack of concentration. }\end{array}$ & $39 \%$ & High \\
\hline 2 & $\begin{array}{l}\text { Non-condusive } \\
\text { environment in the } \\
\text { classroom. }\end{array}$ & $33 \%$ & High \\
\hline 3 & $\begin{array}{l}\text { Communication } \\
\text { problems. }\end{array}$ & $28 \%$ & High \\
\hline 4 & Low cognitive level. & $28 \%$ & High \\
\hline 5 & $\begin{array}{l}\text { Lack of specific teaching } \\
\text { aids. }\end{array}$ & $22 \%$ & High \\
\hline 6 & $\begin{array}{l}\text { The absence of teaching } \\
\text { module. }\end{array}$ & $17 \%$ & Moderate \\
\hline 7 & $\begin{array}{l}\text { Incompatibility of } \\
\text { curriculum. }\end{array}$ & $17 \%$ & Moderate \\
\hline 8 & $\begin{array}{l}\text { Lack of support from } \\
\text { parents. }\end{array}$ & $11 \%$ & Moderate \\
\hline 9 & Discipline problems. & $11 \%$ & Moderate \\
\hline 10 & Lack of aids support. & $11 \%$ & Moderate \\
\hline 11 & Low mobility skills. & $6 \%$ & Low \\
\hline 12 & $\begin{array}{l}\text { The absence of } \\
\text { intervention programs } \\
\text { and therapies. }\end{array}$ & $6 \%$ & Low \\
\hline 13 & $\begin{array}{l}\text { Emotional instability } \\
\text { among teachers. }\end{array}$ & $6 \%$ & Low \\
\hline 14 & $\begin{array}{l}\text { Unassertive among } \\
\text { teachers. }\end{array}$ & $6 \%$ & Low \\
\hline 15 & $\begin{array}{l}\text { Low understanding about } \\
\text { students with multiple } \\
\text { disabilities. }\end{array}$ & $6 \%$ & Low \\
\hline
\end{tabular}


Based on Table 3.0, it is found out that there were 5 problems that were at a high priority level, namely (1) emotional disturbance and lack of concentration (2) non-condusive environment in the classroom (3) communication problems (4) low cognitive level and (5) lack of specific teaching aids. It also showed that the main problems were related to the aspects of teaching aids, accommodation and students' self-problems such as communication, emotional and cognitive development.

\section{Discussion}

Based on the findings, the main problems of special education teachers in Muar in teaching students with multiple disabilities were related to the aspects of teaching aids and the problems faced by the students themselves in terms of self-motivation, self-confidence and communication. This is an indicator for teachers, school administrators and the Ministry of Education to provide special facilities for special needs students so that they can receive more effective education. This coincided with Maslow's Hierarchy of Needs where it stated that the physiological needs must be met first before stepping to the next level of needs (Xiaoqin, 2016; Maslow, 1954). It also covers the physiological needs of sensory and sensorimotor development among students with multiple disabilities which will be formed only through a catalyst such as teaching aids, aids support and appropriate co-curricular activities. This is supported by various studies that have been conducted regarding the development of assistive technology devices for the use of children with multiple disabilities (Ann \& Maclaine, 2013; Proenca et al., 2014; Rufus et al. 2015). The findings also indicate that the problems related to the education system, including curriculum, modules, co-curricular activities, training and courses were not the problems at the level of high priority. This may be due to the improvement of the special education system in Malaysia which included the implementation of new curriculum and assessment namely Standard Curriculum for Primary Schools-Special Education or Kurikulum Standard Sekolah Rendah Pendidikan Khas (KSSRPK) which was implemented in 2011 and Alternative Assessment of Primary Schools or Penilaian Alternatif Sekolah Rendah (PASR) that were implemented in 2016. Meanwhile, Standard Curriculum for Secondary Schools-Special Education or Kurikulum Standard Sekolah Menengah Pendidikan Khas (KSSMPK) will be implemented nationwide in 2017. Multiple disabilities students need special assessment and must be actively involved in the assessment process (Susheel et al. 2015) and the implementation of the IEP need to be monitor effectively (Tamika et al. 2013). This indicates that the formation of curriculum and assessment for special education can reduce the problems faced by the special education teachers in teaching and learning process. The findings of interviews have found out other related problems such as emotional disturbance and lack of concentration, low cognitive level, lack of support from parents, discipline problems, the absence of intervention programs and therapies, emotional instability among teachers, unassertive among teachers and low understanding about students with multiple disabilities. Mrs. Nursyahirah, 32 years stated that:

"Special students typically always less focused in class. Sometimes when he's not emotionaly stable, the teacher had problems to teach. "

Emotional disturbance and lack of concentration $(39 \%)$ in the teaching process is also submitted by 6 other respondents. Mrs. Siti Aminah Nor, 32 years share her opinion that:

"IQ for multiple student is very low. So, when a student in the class was over crowded, the teacher having difficulty to teach and can not face to face with the multiple student."

Low cognitive level and non-condusive classroom will further complicate the process of teaching and learning because the face to face technique can not be implemented to meet the needs of attention of the students. Mr. Abdul Rahman, 52 years old, in a statement said:

"This multiple boy sometimes creates discipline problems such as disturbing his friend and frequently not coming to school."

Disciplinary problems and absenteeism are often one of the global issues among pupils with special needs in Malaysia and this is no exception to students with multiple disabilities. Lack of support from parents also often create difficulty for teachers to better understand the characteristics of the children and this will cause the process of teaching and learning becoming less effective. This is consistent with feedback from Mr. Abdul Halim, 41, who said:

"Sometimes special education teacher did not understand what is actually multiple disabilities students. If you do not understand, how are you going to teach them? The teacher should know the characteristics, appropriate teaching aids and the student's problems."

Emotional instability, insecurity and a low stage of patience among the special education teacher itself is a problem as expressed by Mrs Aishah, 52 years old:

"Becoming special education teacher that teaches severe pupils needs a lot of patience and emotionally stable when coming to school. But when teaching them, teacher need to be firm especially regarding rules." 


\section{CONCLUSION AND SUGGESTION}

The impact of this research is the ability of the authorities or the teachers themselves to set steps to overcome the problems encountered in teaching students with multiples disabilities step by step and thus, able to save time and energy because the targeted problem is precise and not stray. The presence of groups or individuals with multiple disabilities is indeed in a very small population and without realizing it, this minority population had tested the concern and empathy among the majority. Special needs students need to have proper education and compatible to their needs (IDEA 2004). Thus, an analysis of the problems

\section{REFERENCES}

Ann C. Orr \& McLaine Mast. 2013. Tablet-Based Communication And Children With Multiple Disabilities: Lessons From The Clinical Setting. Journal of Social And Behavioral Sciences. 141 : $138-142$.

Bradley N. Hedrick, Norma J. Stumbo, Jay K. Martin, Liam G. Martin, David L. Nordstrom \& Joshua H. Morrill Morrill. 2012. Personal Assistant Support for Students with Severe Physical Disabilities in Postsecondary Education. Journal of Postsecondary Education and Disability. 25(2) : $161-177$.

Centre For Parents Information and Resources. 2013. Multiple Disabilities. Adapted from http://www. parentcenterhub.org[14 Jun 2016].

Emery, D. W. \& Vadenberg, B. 2010. Special Education Teacher Burnout and ACT. International Journal of Special Education. 25(3) : 119-131.

Esther I. Wilder. 2002. The Needs of Individuals With Disabilities in Oklahoma. Oklahoma Disability Report. Adapted from https://apps.ok.gov/ odc/About_ODC/ Disability_ Report/index[11 November 2016].

Fred P. Orelove, Dick Sobsey \& Rosanne K. Silberman 2004. Educating Children With Multiple Disabilities. Baltimore: Paul H. Brookes Publishing.

IDEA. 2004. IDEA 2004 : Building The Legacy. Adapted from http://idea.ed.gov/part-c/statutes [13 Jun 2016].

Jessica A. Klenk \& Lisa A. Pufpaff. 2011. A Case Study Of Tack Tiles Literacy Instruction For A Student With Multiple Disabilities Including Congenital Blindness. Journal of Physical Disabilities: Education and Related Services. 48-66.

Malaysia. 2008. Akta Orang Kurang Upaya 2008 (Akta 685). faced by special education teachers in educating these people is compulsary because the teacher is part of the education system. The solution that emerges from the analysis of these issues will ensure that students receive proper education from high quality special education teachers. This is the mandate that must be upheld by the teachers to ensure that students achieve optimum level of self-potential and be independent as stated at the highest level in the Maslow's Hierarchy of Needs. Therefore, all parties involved need to work together and collaborate to ensure that students with multiple disabilities can receive a wide range of high-quality level of education.

Manuel López-Torrijo \& Santiago MengualAndrés. 2014. Students with Severe, Permanent Disabilities and Their Educational Inclusion in Spain. International Education Studies. 7(2) : 91-105.

NCES. 2016. Children and Youth with Disabilities. Adapted from http://nces.ed.gov/programs/

NCLB. 2001. Improving The Academic Achievement Of The Disadvantged. Adapted from http://www2. ed.gov/policy

Nijs S., Vlaskamp C. \& Maes B. 2016. Children With PIMD In Interaction With Peers With PIMD Or Siblings. Journal of Intellectual Disability Research. 60 (1) : 28-42.

Noraini Ahmad, Zamri Mahamod \& Zahara Aziz. 2012. Communication Skill Teaching For Severe Learning Disabilities Pupils. Malay Language Educational Journal. 2(2) : 11-18.

Norshidah Mohd Salleh \& Manisah Mohd Ali. 2010. Students with Visual Impairments and Additional Disabilities. Procedia Social and Behavioral Sciences. 7 : 714-719.

Pinar Safak, Muzeyyen Eldeniz Cetin \& Mehtap Kot. 2014. Siblings Attitudes Towards Persons With Severe/Profound And Multiple Disabilities In Turkey. Journal of Social and Behavioral Sciences. 191 : 2083 - 2088.

Proenca, Joao Pedro, Quaresma, Claudia, Vieira \& Pedro. 2014. New Application: Adaptation of Toys For Children With Multiple Disabilities. Procedia Technology. $17: 351-358$.

Rufus Olanrewaju, Nalado Abubakar \& Patricia Kwalzoom. 2015. Using Assistive Technology in Teaching Children with Learning Disabilities in the 21st Century. Journal of Education and Practice. 6(24) : 14-20.

Sabitha Marican. 2006. Penyelidikan Sains Sosial Pendekatan Pragmatik. Batu Caves : Edusystem. 
Sherri L. Jackson. 2006. Research Methods and Statistics - A Critical Thinking Approach. USA: Thomson Wadsworth.

Stacie B. Whinnery \& Keith W. Whinnery. 2012. Effects Of Increased Mobility Skills On Meaningful Life Participation For An Adult With Severe Multiple Disabilities. Journal of Physical Disabilities : Education and Related Services. 27-40.

Susheel Joginder Singh, Teresa Iacono \& Kylie M. Gray. 2015. Interactions of pre-symbolic children with developmental disabilities with their mothers and siblings. International Journal of Language and Communication Disorders. 50(2) : 202-214.
Tamika P. La Salle, Andrew T. Roach \& Dawn McGrath. 2013. The Relationship Of IEP Quality To Curricular Access And Academic Achievement For Students With Disabilities. International Journal Of Special Education. 28(1) : 135-144.

Xiaoqin. 2016. Motivation Management Of ProjectBased Learning For Business English Adult Learners. International Journal of Higher Education. 5(3) : 137-145. 